\title{
Chronic Granulomatous Wound Due to Missed Silastic Drain
}

\author{
Sang-Yeul Lee, Kun-Yong Sung \\ Department of Plastic and Reconstructive Surgery, Kangwon National University College of Medicine, Chuncheon, Korea
}

\begin{abstract}
Chronic granulomatous lesion can mimic surgical wound inflammations, abscesses, ganglion cysts, lipomas or neoplastic lesions. We report a case of a patient with a recurrent chronic granuloma $\left(1 \times 1 \mathrm{~cm}^{2}\right)$ of the right cheek that was refractory to conservative measures. On radiologic examination, a $5 \mathrm{~cm}$ linear radioopaque material was detected. The patient underwent explorative surgery and a silastic drain was found that was not removed ten years ago after reduction of a zygomatic fracture. A unique case of a misplaced silastic drain that was put 10-year ago, presenting itself as a chronic granulomatous lesion is reported.
\end{abstract}

Keywords: Foreign body, Chronic granulomatous lesion, Silastic drain

\section{Introduction}

A silastic drain is often inserted at the surgical site after reduction of facial bone fractures to minimize the formation of hematoma. But if not removed adequately, these drains may act as foreign bodies and induce chronic granulomatous wound. 1,2,3,4,5 These chronic granulomatous wound may be misdiagnosed as other lesion, such as abscess, epidermal cyst, or other neoplasm. The authors have experienced a case of a chronic granulomatous wound treated with wide excision and primary closure, and report our experience.

\section{Case illustration}

A 61-year-old man with a past history of facial bone fracture presented to our hospital with a progressive dimpling on his right cheek. Ten years ago, he underwent open reduction and internal fixation of the tripod fracture. Other than this surgery, he had no other medical or traumatic history. However, 3 months ago a painless firm nodule (1 $\mathrm{cm}$ in diameter) appeared beneath the skin of the right cheek that enlarged with time. The nodule was primarily diagnosed as an epidermal cyst in a local dermatologic clinic, and the patient was put on antibiotics, but showed little improvement. He was referred to our plastic surgery department due to the worsening of the skin wound accompanied by local heating and pain. On radiologic examination, a $5 \mathrm{~cm}$ linear radio-opaque material was seen, with underlying titanium plates and screws (Figure $1 \mathrm{~A}$ ).

During the process of general anesthesia, pressure to the wound revealed the tip of silastic drain (Figure 1B). On careful dissection, it was apparent that the origin of

\begin{tabular}{l} 
Case Report \\
updates \\
Received: April 9, 2017 \\
Revised: April 29, 2017 \\
Accepted: May 6, 2017 \\
Corresponding author: \\
Kun-Yong Sung, M.D., Ph.D. \\
Department of Plastic and Reconstructive \\
Surgery, Kangwon National University \\
Hospital, Kangwon National University \\
College of Medicine, 156 Baengnyeong-ro, \\
Chuncheon 24289, Korea \\
Tel: +82-33-258-9494 \\
Fax: +82-33-258-9437 \\
E-mail: ps@kangwon.ac.kr \\
No potential conflict of interest relevant to this \\
article was reported. \\
\hline This is an Open Access article distributed under the \\
terms of the Creative Commons Attribution Non- \\
Commercial License (http://creativecommons.org/ \\
licenses/by-nc/4.0/) which permits unrestricted non- \\
commercial use, distribution, and reproduction in any \\
medium, provided the original work is properly cited. \\
o 2017 The Korean Wound Management Society
\end{tabular}



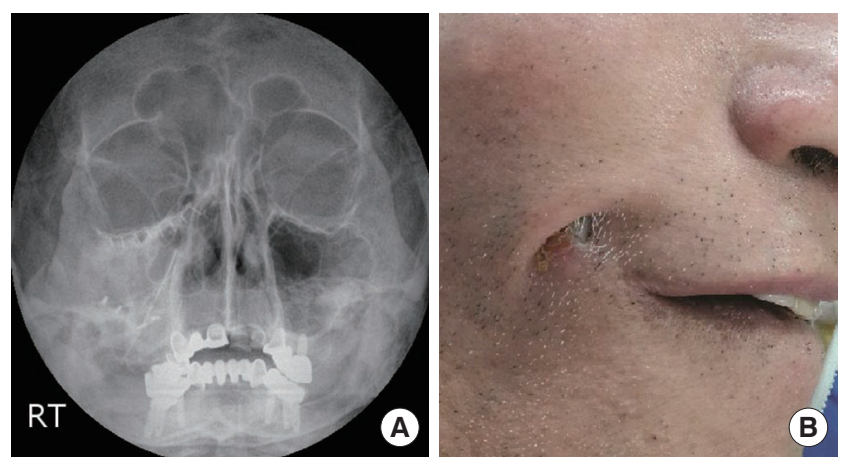

Figure 1. (A) On the radiologic examination, $5 \mathrm{~cm}$ linear radioopaque material, titanium plate and screw was detected. (B) During the process of general anesthesia, pressure to the wound revealed the tip of silastic drain.

the wound was from the silastic drain. It is guessed that the drain was not removed at the 10 years ago surgery (Figure 2). The granulomatous wound was widely excised and closed primarily. Antibiotics (cefazoline) for common skin bacterial pathogens were administered. Subsequent follow-up of the patient for 6 months revealed no complications and a good healing of the wound.

\section{Discussion}

The use of silastic drains after facial bone surgery is an old and well-established technique for the prevention of hematomas. Generally, these drains are removed within a week to prevent ascending infection. Because of its radiolucency, identification of a silastic drain on the radiograph is often difficult. In case the silastic drain has been misplaced, complete removal of the drain is essential for the prevention of infections.

Laxenaire et al. ${ }^{6}$ found from his cohort of 137 patients that fibrous capsule formation, fistulas, and infections may be associated with silicone implantation. Another study has documented late extrusion of silicone implants through the facial skin at 10,16 , and 17 years after surgery.

Foreign body granulomatous reactions develop after a variable period of time ranging from 5 months to 15 years. ${ }^{8,9}$ The clinical manifestations may vary from simple swelling, hardening, and tenderness to mild inflammation, burning sensations, and even fibrous reactions. ${ }^{10,11}$

Complications of periorbital reconstruction are numerous and we may classify them as orbital or sinus complications, depending on the site of the inflammatory process. Among orbital complications, periorbit cellulitis, dacryocystitis, and

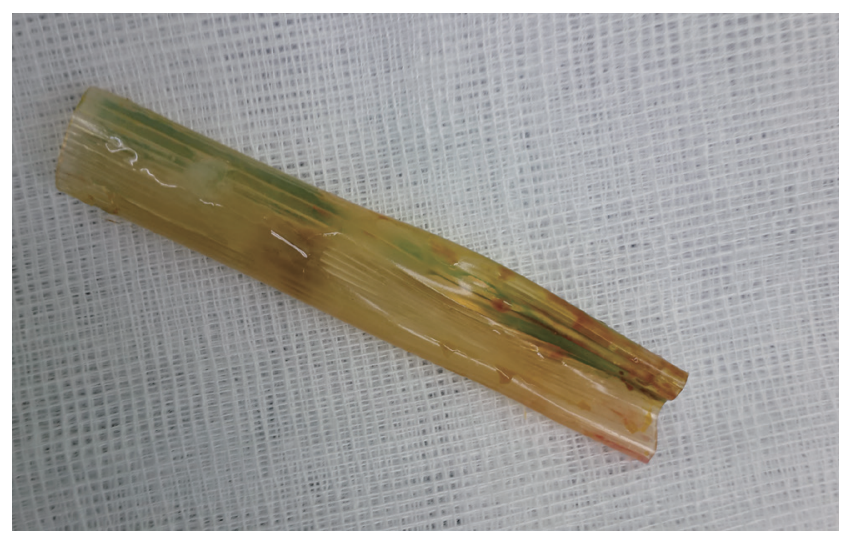

Figure 2. The 10-year misplaced silastic drain that presented as chronic granulomatous lesion.

diplopia are described, and several cases of cystic neoformation surrounding silastic sheet are reported..$^{12,13}$

The most common sinus complication is sinusitis, associated to rhinitis and purulent discharge; in literature, a case of bilateral sinusitis is described due to the silastic sheet perforation of the bony nasal septum and migration to the contralateral nasal cavity. ${ }^{14}$

Chronic granulomatous wound forming after periorbital reconstructions is not common. This case reminds the surgeon that radiologic examination of a chronic skin lesion is essential for diagnosis, and that any misplaced silastic drains must be removed after operation.

\section{Referrence}

1. Lee DH, Joo YE, Lim SC. Migrated orbital silastic sheet implant mimicking bilateral sinusitis. J Craniofac Surg 2011; 22:2158-9.

2. Andrews AE, Hicklin L. Inflammatory nasal polyps: an unusual late complication of silastic sheet repair of orbital floor fracture. J Laryngol Otol 2006;120:e1

3. Awan MA, Cheung CM, Sandramouli S, et al. An unusual late complication of orbital floor fracture repair. Eye (Lond) 2006;20:1454-55.

4. Pero CD, Nuss DW. Transnasal endoscopic removal of orbital, ethmoid sinus, and anterior skull base foreign body with mucocele formation. Skull Base 2008;18:417-22.

5. Saussez S, Filleul O, Mahillon V, et al. Maxillary sinusitis caused by the migration of a silastic implant used for an orbital floor reconstruction: a case report. B-ENT 2010;6:299-301.

6. Laxenaire A, Levy J, Blanchard P, et al. Complications of silastic implants used in orbital repair. Rev Stomatol Chir Maxillofac 1997;98:96-9.

7. Miyasaka M, Tanaka R, Hanai U, et al. A case of chronic in- 
fection 28 years after silicone orbital implant. Tokai J Exp Clin Med 2008;33:35-8.

8. Lombardi T, Samson J, Plantier F, et al. Orofacial granulomas after injection of cosmetic fillers. Histopathologic and clinical study of 11 cases. J Oral Pathol Med 2004;33:115-20.

9. Ficarra G, Mosqueda-Taylor A, Carlos R. Silicone granuloma of the facial tissues: a report of seven cases. Oral Surg Oral Med Oral Pathol Oral Radiol Endod 2002;94:65-73.

10. Kaprana A, NE foentanlabis, A Karatzanis, et al. Suture granuloma presenting as a lateral neck mass. Otorhinolarnyngologica - Head and Neck Surgery 2012;48:36-40.

11. Sanchis-Bielsa JM, Bagán JV, Poveda R, et al. Foreign body granulomatous reactions to cosmetic fillers: a clinical study of 15 cases. Oral Surg Oral Med Oral Pathol Oral Radiol Endod 2009; 108:237-41.

12. Nitsche T, Yousefpour A, Bainton R. Chronic orbital infection caused by migration of an orbital silastic implant. Int J Oral Maxillofac Surg 2008;37:90-2.

13. Gregory GF. Silicone-associated tissue reaction: a dilemma for oral and maxillofacial surgeons. Br J Oral Maxillofac Surg 1995;33:180-4.

14. Lee DH, Joo YE, Lim SC. Migrated orbital silastic sheet implant mimicking bilateral sinusitis. J Craniofac Surg 2011;22: 2158-9. 